\title{
Laço social como discurso na psicose: impasses e possibilidades
}

\author{
Social bond as discourse in psychoses: \\ impasses and possibilities
}

\author{
Vínculo social como discurso en psicosis: \\ callejones sin salida y posibilidades
}

\section{Maria Clara Carneiro Bastos ${ }^{1}$ (D) Rogério de Andrade Barros²}

\begin{abstract}
1Autora para correspondência. Universidade Estadual de Feira de Santana (Feira de Santana). Bahia, Brasil. contatomariaclaraa@gmail.com
\end{abstract} Universidade Estadual de Feira de Santana (Feira de Santana). Bahia, Brasil. contaterogerio@gmail.com

\begin{abstract}
RESUMO | INTRODUÇÃO: A abordagem psicanalítica atua no avesso do discurso psiquiátrico, não requerendo um manejo padronizado, e se orientando para a singularidade. O modo como cada um se enlaça ao Outro é apresentado por Lacan (1969-1970/1992) através do conceito de laço social. A inserção no discurso engendra uma trama social e, para tanto, é necessário observar o modo singular com que cada um faz laço, valendo-se da ideia de que haverá sempre um resto, pedaço de real não completamente absorvido pela lógica discursiva. Será propriamente através da invenção de um sinthoma que este resto encontrará alguma estabilização, inserindo o Outro nesta construção (Lacan, 1975-1976/2007). Partindo deste a priori, o presente estudo objetiva delinear como se estabelece o laço social na psicose a partir da psicanálise de orientação lacaniana, articulando com o conceito de sinthoma. MÉTODO: O percurso metodológico adotado se caracteriza como qualitativo, de objetivo exploratório, e quanto ao seu delineamento, é uma pesquisa bibliográfica. RESULTADO: Como resultados, identificamos que a psicanálise possibilita uma clínica pautada na responsabilidade do sujeito e de sua singularidade como diretrizes éticas na condução de intervenções no campo da saúde mental. CONCLUSÃO: É a partir do conceito de laço social, formulado por Lacan, que poderemos ver as soluções, bricolagens e sinthomas que amparam a cada um. Portanto, resta acompanhar e testemunhar, no um a um dos casos, a forma como cada sujeito pode, ao seu modo, remendar a sua realidade, sempre psíquica.
\end{abstract}

PALAVRAS-CHAVE: Psicanálise. Saúde Mental. Laço Social. Psicose.

ABSTRACT | INTRODUCTION: A psychoanalytic approach does not require psychiatric discourse, standardized management, and uniqueness. METHOD: Or how each is linked to the Other is presented by Lacan (1969-1970/1992) through the concept of the social bond. A non-discursive insertion engenders a social fabric, and, therefore, it is necessary to observe the singular form in which each face, starting from the idea that there will always be a rest, a piece of the real, is not totally absorbed by the discursive logic. Through the invention of a symptom, this rest will find some stabilization, insertion, or other construction (Lacan, 1975-1976/2007). Based on this a priori, or the present study, the objective is to understand how the social bond in the psyche is established from Lacanianoriented psychoanalysis, articulating itself as a symptom concept. The methodological approach is qualitative, with an exploratory objective, and its design and bibliographic research every year. RESULT: As a result, we identified that psychoanalysis enables a clinic based on the individual's responsibility and its uniqueness as ethical guidelines in conducting interventions in the field of mental health. CONCLUSION: From the concept of the social bond formulated by Lacan, we will be able to see the solutions, bricolages, and symptoms that each one protects. Therefore, it remains to monitor and testify, not one to two cases, as each subject can, in his own way, fix his reality, always psychic.

KEYWORDS: Psychoanalysis. Mental Health. Social Bond. Psychosis. 
RESUMEN | INTRODUCCIÓN: El enfoque psicoanalítico trabaja en el lado opuesto del discurso psiquiátrico, no requiriendo un manejo estandarizado y enfocándose en la singularidad. La forma en que cada uno se vincula con el Otro es presentada por Lacan (1969-1970 / 1992) a través del concepto de vínculo social. La inserción en el discurso engendra un tejido social y, por tanto, es necesario observar la forma única en que cada uno forma un vínculo, haciendo uso de la idea de que siempre habrá un remanente, un trozo de realidad no completamente absorbido por la lógica discursiva. Será precisamente a través de la invención de un sinthome que este remanente encontrará cierta estabilización, insertando al Otro en esta construcción (Lacan, 1975-1976 / 2007). Partiendo de este a priori, el presente estudio pretende esbozar cómo se establece el vínculo social en la psicosis a partir del psicoanálisis lacaniano, articulándolo con el concepto de sinthome. MÉTODO: El enfoque metodológico adoptado se caracteriza por ser cualitativo, con objetivo exploratorio, y su diseño es una investigación bibliográfica. RESULTADO: Como resultado, identificamos que el psicoanálisis posibilita una clínica basada en la responsabilidad del sujeto y su singularidad como pautas éticas en la realización de intervenciones en el campo de la salud mental. CONCLUSIÓN: Es a partir del concepto de vínculo social, formulado por Lacan, que podremos ver las soluciones, bricolages y sinthomes que sustentan cada uno. Por tanto, queda por seguir y presenciar, en uno a uno de los casos, cómo cada sujeto puede, a su manera, remendar su realidad, siempre psíquica.

PALABRAS CLAVE: Psicoanálisis. Salud mental. Vínculo social. Psicosis.

\section{Introdução}

Partimos de uma leitura particular sobre as engrenagens sociais e sua interlocução com as patologias da alma (Foucault, 1978), compreendendo-as como um sistema de normas e valores que estruturam formas de ação e julgamento. Os constructos sociais se apresentam para além de estruturas normativas explícitas, mas se constituem, também, por meio de um conjunto implícito de disposições de condutas e normas enunciadas (Safatle et al., 2020). A norma como menção à normalidade, traz à baila aquilo que se considera patológico ou não patológico, porém, é imprescindível analisar com mais atenção o que é nomeado como loucura e o sujeito louco (Basaglia, 1991; Canguilhem, 2009; Maher \& Maher, 2011).

É levando em conta a inexistência de uma sociedade que não se fundamente de complexos processos de produção e gestão de patologias, que o sofrimento psíquico passa a ser concernido como um sofrimento socialmente compreendido como: excessivo ou faltoso e objeto de intervenção médica que mira a adequação da vida a valores socialmente estabelecidos. Nesse sentido, o sofrimento patológico traz em seu bojo, indissociavelmente, modalidades de intervenções clínicas e juízos de valores (Safatle et al., 2020).

A dinâmica social não se restringe à internalização de disposições normativas, mas oferece uma gama de quadros patológicos oferecidos pelo saber médico, sempre em confluência com os mestres discursivos de uma época (Tendlarz, 2007; Calazans \& Bastos, 2008; Seldes, 2019). Assim, “não se socializa apenas através da enunciação da regra, mas principalmente através da gestão das margens" (Safatle et al., 2020, p. 9).

Freud (1929-1930/2010a) em O mal-estar na civilização já denunciava que o mal-estar é uma condição da existência humana em sua relação com a civilização. Frente à essa condição, cada sujeito pode, servindo-se da cultura e das interdições à satisfação pulsional impostas por ela, construir uma trajetória particular na vida. Pensar nas patologias sociais na contemporaneidade corresponde a uma reflexão da disseminação de categorias que descrevem um movimento de patologização que perde de vista o singular de cada sujeito, orientando-se através da generalização das subjetividades ao invés de centralizar-se a partir da singularidade (Arenas, 2011; Laurent, 2017).

O sintoma para Freud (1929-1930/2010a) é a via pela qual o sujeito vai readquirir, de maneira deformada, a satisfação pulsional que fora barrada pelas normas e regras sociais. Essa proposição de Freud evidencia um contraponto político diante da perspectiva patologizante da sociedade orientada pelo saber médico-psiquiátrico (Aguiar, 2020). Essas formulações freudianas permitem a Lacan (1969-1970/1992) demarcar que, através da cultura, entendida especialmente na sua relação com a linguagem, os seres falantes podem produzir seu próprio discurso, construindo sua história e se servindo da ordem simbólica vigente, pautada em códigos compartilhados e leis que lhes são comuns. 
Na via oposta aos mestres discursivos contemporâneos, Lacan (1969-1970/1992) considera que a entrada no discurso é o que propriamente podemos chamar de laço social. É através da partilha simbólica que o animal humano se culturaliza. Como discurso, o laço social é uma forma de vínculo entre os seres de fala (Porge, 2006). Existe uma ligação entre o sujeito e o Outro que, representado pelas articulações significantes dentro do discurso, produz atos e condutas, numa correlação que torna sincrônica a ordem singular e pública. Destarte, o que está em jogo é o ordenamento e a regulação do vínculo entre os sujeitos (Coelho, 2006).

O discurso ultrapassa a palavra, as enunciações efetivas, já que subsiste em certas relações fundamentais, definindo e sustentando os modos de laço. Para psicanálise de orientação lacaniana, a inclusão no campo social está associada à articulação do sujeito com a linguagem e com a cultura pois não há sujeito sem um Outro. A concepção de si, portanto, só se estabelece na alteridade, a partir da compreensão desse Outro que invoca seu desejo (Lacan, 1958/1998). Dessa forma, a conceituação de sujeito é individual e coletiva, ilustrando a inferência do laço social ainda que nas relações mais rudimentares da vida cotidiana (Lacan, 1969-1970/1992).

Pensar a loucura como condição indissociável do humano, apresentando-se como produto e produtora de seu contexto, possibilita percebê-la como tentativa de enfrentamento de cada um, na sua particularidade, às amarras e imposições sociais. A partir dessa perspectiva, existe possibilidade de pensar o laço social na estrutura psicótica (Lacan, 19691970/1992), uma vez que o discurso engendra uma trama social, onde o louco, a seu modo, também estabelece vínculos com aquilo que corresponde a sua realidade psíquica.

A psicanálise se opõe ao processo de homogeneização e universalização do sofrimento, compreendendo o sujeito diante das possibilidades de sua estrutura, tentando ao seu modo fazer um laço social a partir da particularidade da construção da sua realidade psíquica (Quinet, 2018). A leitura proposta no presente artigo apreende que a patologia psiquiátrica normalista não corresponde ao real da psicanálise, já que esta parte da singularidade do ser falante que se enlaça em seu sinthoma (Lacan, 1975-1976/2007) no campo social, resistindo à universalização.
Neste ínterim, a lacuna epistêmica que sustenta esta produção concerne-se a partir da identificação de estudos teóricos que apresentam o conceito psicanalítico de laço social e sua articulação com a psicose (Generoso, 2014; Mendes, 2005; Pereti, 2011; Silva \& Derzi, 2019), entretanto, não alcançam as considerações lacanianas de seu último ensino, especialmente, acerca do conceito de sinthoma, o que assegura seu ineditismo.

Partindo deste a priori, o presente estudo objetiva delinear como se estabelece o laço social na psicose a partir da psicanálise de orientação lacaniana, articulando-o com o conceito de sinthoma. Esse objetivo geral se desdobra nos seguintes objetivos específicos: fazer uma revisão de literatura acerca do conceito de laço social, articulando-o com o conceito de sinthoma, e diferenciando o laço social na neurose daquele que ocorre na psicose.

\section{Método}

A presente pesquisa trata-se de uma proposta de caráter qualitativo, que como tal, se preocupa com um nível de realidade que não pode ser quantificável nem reduzido à operacionalização de variáveis, já que trabalha com o universo de significados, aspirações, crenças e valores que são subjetivos (Minayo, 1994).

Configura-se também, quanto a seus objetivos, como uma pesquisa de tipo exploratório, uma vez que, visa proporcionar uma visão geral sobre um determinado fato, especialmente, relacionado a temas pouco explorados (Gil, 2008).

No que tange ao delineamento da pesquisa, ela se dará como uma pesquisa bibliográfica. Cervo e Bervian (1983) escrevem que a pesquisa bibliográfica "explica um problema a partir de referenciais teóricos publicados em documentos" (p. 55). Por esta afirmação é possível inferir então que, quando o pesquisador se propõe a fazer uma pesquisa bibliográfica, está convicto que deverá, com base nessa pesquisa, explicar ou apresentar um resultado para uma determinada situação, que será sua contribuição para a ciência ou área de atuação. 
Por ser uma pesquisa em psicanálise, destacam-se particularidades referentes à construção de saber nesse campo. Para tanto, é necessário reconhecer o lugar da psicanálise em denunciar um furo no conhecimento, apontando um não saber sobre o que não se esgota pela via das palavras, o que implica sempre um limite do que é passível de compreensão, fazendo com que ela esteja envolta em "pensar as possibilidades de construção de uma epistemologia que contemple a incompletude, que não se esquive quanto às exigências do não-objetivável" (Rodrigues et al., 2005, p. 107). Nessa aposta, não se pretende esgotar o tema da psicose numa tentativa equivocada de tamponar as falhas intrínsecas à construção do conhecimento. Desse modo, este trabalho se situa na perspectiva indicada por Mezêncio (2004), em que "as lacunas do texto levam às perguntas, e o método psicanalítico ensina que a verdade está aí e não na resposta" (p. 112).

A metodologia adotada parte da especificidade da psicanálise no tocante à implicação do sujeito, em que o desejo do pesquisador está situado, seja no interesse de investigar o tema e mesmo na relação de extimidade (Lacan, 1957-1958/2008) que o acompanha no decorrer do processo, sem que saiba especificar que aspecto é esse que intimida e atrai, concomitantemente.

Os dados coletados na pesquisa bibliográfica (Cervo \& Bervian, 1983) foram analisados a partir de publicações e estudos acerca da Saúde Mental e da psicanálise no campo das psicoses, especialmente, articulando os conceitos de laço social (Lacan, 1969-1970/1992) e sinthoma (Lacan, 1975-1976/2007). Ademais, a publicação respeita a Resolução Consepe $N^{\circ}$ 067/2017 que institucionalizou o projeto de pesquisa: "O conceito de sinthoma em Lacan e suas consequências clínicas", na Universidade Estadual de Feira de Santana (UEFS), através do Laboratório de Pesquisa em Psicanálise (LAPPSI), onde a presente investigação está vinculada.

\section{Resultados e discussões}

\section{Da universalização da saúde à singularidade do desejo}

No contexto de instauração da normalidade, da universalização da saúde, da ditadura pela homogeneização do singular, onde está a loucura na contemporaneidade? Em qual lugar a psicanálise reivindica ou recusa a postura psiquiátrica frente à loucura de cada um?

A psiquiatria e a psicopatologia, como foram apresentadas, inserem-se e normatizam a lógica do todo, partindo de constructos universais para classificação do humano (Gaspard, 2012). Por sua vez, a ética em psicanálise parte da singularidade da relação do sujeito com o seu desejo e seu gozo (Miller, 2012). Por essa proposição, entende-se que cada sujeito em si é potencialmente diferente.

É interessante notar que a partir de tal compreensão psicanalítica abre-se um paradoxo: a grande competência do discurso analítico é sua maior adversidade, pois, a postura analítica parte da lógica do não-todo (Lacan, 1972-1973), do caso a caso, onde não lhe cabe descrever o universal, mas alinhar a escuta para as invenções do um por um (Barreto, 2007).

Dos pressupostos epistemológicos à prática psicanalítica, identificamos um percurso metodológico e ético distinto do saber psiquiátrico preponderante. A psicanálise, como aposta no inconsciente, acolhe o sujeito de pleno direito (Miller, 2011) como ser particular, possibilitando localizá-lo em seu dizer. A nova práxis criada por Freud oferta escuta para o sujeito que o racionalismo recusou, desconsiderando uma verdade universal pré-estabelecida e buscando compreender a verdade que cabe ao próprio sujeito. Sendo assim, "a psicanálise não vai colocar a questão do sujeito da verdade, mas a questão da verdade do sujeito" (Garcia-Roza, 2009, p. 23).

Freud toma seu rumo na direção do inconsciente, lançando a psicanálise numa nova referência que redimensiona o alcance do diagnóstico, que vai da descrição à dinâmica, do fenômeno à estrutura (Mezza, 2018). Uma nova proposta se delineia por oposição ao campo fenomênico-descritivo da psiquiatria e da psicopatologia, dirigindo-se ao saber de ordem inconsciente e suas formações (Freud, 1917/1980). Para tal, o inconsciente não é da ordem do mental (Miller, 2011), mas da estrutura significante que organiza o mental.

A proposta de intervenção psicanalítica não é de eliminar um sintoma, pois é por meio dele que cada sujeito tem a possibilidade de encontrar sentido a sua existência, mas de pensar caminhos possíveis para 
construção de novos modos de enfrentamento ao mal-estar (Lacan, 1975-1976/2007). É neste ínterim que a psicanálise opera com a função de um sujeito pleno de direito e encontra espaço para legitimar a associação livre e as manifestações inconscientes, seja com os sintomas, atos falhos, lapsos etc.

As proposições psicanalíticas delineiam a proposta de saúde como algo não comum ou coletivo, mas sim a partir do modo como cada sujeito objeta, resiste, à sua maneira, ao impulso de ser enquadrado na universalização a qual não se encaixa e na qual não há lugar para sua loucura singular (Recalde, 2011; Arenas, 2011). Para tal fim, quando Lacan (1975-1976/2007) fórmula que todo mundo delira ou que vivemos em uma espécie de delírio generalizado (Miller, 1999), isto nada mais é que uma tentativa de explicar que cada um, ao seu modo, tenta lidar com sua a emergência do real de seu gozo, significando-o a partir de construções inconscientes particulares.

O movimento de universalização da saúde em oposição à loucura de cada um pode ser compreendido como "normalidade delirante" (Berenguer, 2011) que inviabiliza a prática psicanalítica de orientação lacaniana, uma vez que compreende cada caso como único, segundo o estabelecimento do seu laço com a loucura própria, com as soluções singulares. Esta é uma perspectiva iniciada por Freud (1893-1895/2016) nos Estudos sobre a histeria em que parte da história de cada um para assim, compreender suas produções sintomáticas, ou seja, ele sai da rotulação homogeneizadora acerca da histeria, para lidar com o singular de cada caso.

A lógica homogênea do "igual" pode ser pensada, então, como uma alternativa de controle social (Miller, 2011). A loucura aqui descrita a partir da leitura psicanalítica não corresponde com a estrutura psicótica, mas faz referência aos modos particulares de inscrição do sujeito no mundo, através da linguagem (Lacan, 1969-1970/1992), sendo o mundo e suas construções sócio-históricas decisivas para compreensão da loucura de cada ser de fala.

\section{Responsabilidade e a política do inconsciente}

Outra consideração importante diz respeito à responsabilidade. Como nos diz Lacan (1953/1998) "por nossa posição de sujeito, sempre somos responsáveis" (p. 873). Essa noção de responsabilidade abriu espaço para uma postura crítica que não se restringe ao poder da ciência biológica. Ao trazer à baila questões como a hereditariedade, os neurotransmissores e a influência da genética, a clínica de orientação lacaniana aplicada ao campo da saúde mental é fundamentada como a clínica do sujeito de direito e da responsabilidade, entendendo a importância desses fatores, mas não limitando-se a eles.

O sujeito de direito é o sujeito do inconsciente, constituído em sua estrutura. Nesse sentido, Barreto (2007) destaca dois aspectos essenciais: "a subordinação do sujeito à estrutura que o determina e a sua marcação como sujeito fendido" (p.18). No que tangue o primeiro aspecto, a fórmula inconsciente só se torna possível através do discurso, sendo assim, o inconsciente não diz respeito apenas às cargas internas, mas se estabelece a partir da interdependência com a exterioridade linguística. $O$ segundo aspecto considera o sujeito como dividido, sujeito do significado e do significante, mais precisamente pode-se dizer que “o sujeito existe através da ruptura, ele é o lugar da ruptura, ele existe ali mesmo onde há corte" (Barreto, 2007, p.19).

É na atuação clínica que Lacan (1969-1970/1992) apresenta ser possível identificar as nuances de cada ser de fala, perspectiva tão cara à psicanálise, pois é a partir da escuta de cada sujeito que os fenômenos inconscientes desmascaram a estrutura, inscrição particular no campo da linguagem, possibilitando a indicação do Outro (Recalde, 2011).

$\mathrm{Na}$ busca pela compreensão do sujeito frente ao mundo que o compõe motiva a teoria de constituição do Outro. Lacan (1955-1956/1985) introduz o conceito de Outro ao defini-lo como tesouro dos significantes, lugar do registro simbólico, delimitação essencial para legitimar as estruturas psíquicas e seus modos particulares, seja a neurose ou psicose.

Ao se tratar da neurose pode-se falar da importância desse Outro para a configuração de um Eu, como marca de um registro simbólico atuante. Já na clínica da psicose, essa comunicação se dá sem mediação efetiva com o registro simbólico, isso se estabelece à céu aberto, estatuto no qual se encontra o inconsciente nessa estrutura. Não obstante, neurótico ou psicótico, cada um encontra nas particularidades de suas estruturas inconscientes maneiras de lidar com a falta, seja ela simbolizada na neurose ou não, como é o caso da psicose. 
Seguindo tal perspectiva, Miller (1981) interroga: "como é possível não estar louco? Por que o sujeito chamado de normal, que não está mais afetado pela palavra, que não é menos xenopata do que o psicótico, não se dá conta disso? Como podemos crer que somos os autores de nossos pensamentos? (p. 58)

Freud (1924/1996) em A Perda da Realidade na Neurose e na Psicose já indica que tanto na neurose como na psicose há remodelação da realidade, no entanto, a construção subjetiva do sujeito frente ao mundo que o compõe será distorcida, seja a neurose, através do mecanismo de recalque ou de um afrouxamento da relação com a realidade, resultado de uma repressão fracassada, e na psicose, por meio do repudio da realidade, tal qual ela se apresenta, e na tentativa de substituí-la.

É partindo dessa interpelação que Lacan retoma a letra freudiana, apostando na palavra para invenção subjetiva inconsciente, realizando uma identificação ao sintoma com o objetivo de demonstrar que somos todos diferentes, não-naturais e vinculados através da nossa comum dependência com a linguagem (Guéguen, 2011). A aposta lacaniana parte da elaboração de um dentro e um fora, um exercício que permita estabelecer uma forma contundente entre $o$ privado do campo analítico e o público das políticas públicas de saúde, fundamentando-se pela ordem da não segregação.

O ensino de Jacques Lacan renovou a perspectiva psicanalítica para além do desejo freudiano coordenado pela norma edipiana e amplia as suas possibilidades de ação e uso (Mezza, 2018). A localização da psicanálise está no laço transferencial que supõe o lugar do Outro. Esse é o espaço em que o inconsciente se manifesta no dizer com maior liberdade. Em face ao discurso igualitário das terapias atuais, o saber psicanalítico investe em ultrapassar as barreiras dos discursos hegemônicos. A psicoterapia ocupa-se de tentar normatizar os sujeitos e eliminar suas manifestações sintomáticas, enquanto a psicanálise está atenta ao laço que o sujeito estabelece com seu sintoma, sobre o qual este diz de sua realidade psíquica.

No que diz respeito a política do inconsciente e a ética em psicanálise, Laurent (2003) indica que o analista se mantém na posição de crítica, onde, historicamente, está despido de toda crença e ideal. Dando possibilidade para que em cada caso a transferência encontre sua função. É justamente nesse âmbito que, a psicanálise é uma prática de desidentificação, onde denuncia práticas sociais e permanece à margem, ao passo que se orienta na contramão dos discursos que sustentam a sociedade contemporânea.

A unicidade do caso clínico é uma maneira política de resistir a classificação tão marcante no signo social. O sujeito em análise inventa seu sintoma como resposta ao real, em que cada um se satisfaz com seu sintoma de modo único, posto que a parceria sintomática é um modo de insistência de satisfação. Isto posto, o sintoma para a psicanálise não cabe nas normativas das patologias médicas, pois corresponde a uma construção inconsciente passível de decifração que diz respeito aos modos de enfrentamento e gozo do sujeito em sua particularidade (Lacan, 19591960/1997; Laurent, 2003).

Para tanto, se a postura médica é de forçar a eliminação do sintoma e, para alcançar tal objetivo, foraclui o sujeito, podemos dizer que a atitude analítica é o seu avesso, direcionando-se ao caso a caso e à política do sintoma, que é uma formação inconsciente, logo, sempre particular. A psicanálise se refaz e se orienta na busca ética e política de uma solução que dê propriamente lugar ao sujeito que, pela fala, produza efeitos na regulação do gozo e oportunize sua maneira própria de fazer laço social (Voruz, 2009).

\section{Laço social na psicose: o delírio como construção de discurso}

Como dito anteriormente, o tratamento psicanalítico atua no avesso do discurso psiquiátrico uma vez que não requer um manejo padronizado, mas uma conduta que leve em consideração a singularidade de cada sujeito, se opondo ao enquadramento e controle da loucura de cada um (Generoso, 2014; Tendlarz, 2011; Guéguen, 2011; Recalde, 2011). Assim, se faz necessário reconhecer os laços sociais como discursos que engendram toda a trama social, que possibilitam a conexão entre o sujeito e a dinâmica coletiva, ainda que sempre reste um pedaço de real não completamente absorvido pela lógica discursiva (Lacan, 1969-1970/1992). 
Propomos um percurso teórico que perpassa por dois momentos da clínica das psicoses: a clínica da foraclusão do Nome-do-Pai, do Lacan (1955-1956/1985) estruturalista, do recurso primordial da linguagem e da psicose como déficit frente ao recurso simbólico da neurose. Em seguida, a clínica do sinthoma (Lacan, 1975-1976/2007), da clínica orientada ao real, tomando o sinthoma como invenção do ser de fala para resolver-se com o irredutível de seu gozo.

A influência estruturalista no ensino lacaniano marca uma leitura específica sobre a linguagem como ordem de determinação da civilização humana, destacando o lugar do registro simbólico, delimitação essencial para legitimar as estruturas psíquicas e seus modos particulares, seja a neurose, psicose ou perversão.

Considerando a estruturação do sujeito no mundo a partir das leis da linguagem, Lacan (1969-1970/1992) sublinha que o discurso permite compreender a relação do sujeito em seu encontro no campo do Outro e os afetamentos advindos disto, que só se torna possível por intermédio da linguagem. $O$ discurso se constitui como um campo definido e estruturado de um saber, sobretudo, o discurso é fundado pela linguagem (Generoso, 2008).

Lacan (1972-1973/1985) apresenta a ideia de discurso, senão, como liame social, fundado sobre a linguagem, que diz respeito à instauração de um laço, na tentativa de organizar uma rede articulada de significantes. Designa o laço social como discurso, onde, "o liame social só se instaura por ancorar-se na maneira pela qual a linguagem se situa e se imprime, se situa onde aquilo que formiga, isto é, o ser falante" (p.74).

O laço social faz referência ao campo do Outro onde "o sujeito não está sozinho com seu Isso" (Lacan, 1969-1970/1992), posto que a constituição de si se encontra balizada pelo olhar de um Outro. Em vista disto, como pensar a possibilidade de instauração do laço social na psicose, por meio das especificidades de uma estrutura que responde pelo real, sem apelo efetivo ao registro simbólico, ao Outro e sua estrutura linguageira?
Lacan (1932/1987) jamais deixou de se interessar pelos estudos acerca da psicose, tema de sua tese de doutorado, intitulada Da psicose paranoica e suas relações com a personalidade. O exercício lacaniano de revisitar Freud denuncia sua postura diante da psicose, entendendo-a segundo sua lógica, especificação e determinação próprias. Assim, a psicose não pode ser compreendida como um mero estado crise, mas sim, diz respeito a uma estrutura clínica que desencadeada ou não tem suas próprias particularidades e manejos específicos.

A psicose como estrutura clínica se revela no dizer do sujeito, correspondendo a um lugar particular na articulação dos registros real, simbólico e imaginário. Destarte, não há tratamento que não seja efetivado através de um discurso, sendo assim, toda proposta de tratamento se insere num laço social.

O humano, como sujeito da linguagem, não pode se esquivar da interação com o universo simbólico, porém, é justamente na relação com o significante que se instauram questões sobre a loucura de cada um. É através desse registro que Lacan demarca as condições imprescindíveis para compreensão do sujeito psicótico: a foraclusão do Nome-do-Pai no lugar do Outro e o fracasso da metáfora paterna.

Quinet (2014) apresenta que a "foraclusão é um neologismo que se utiliza do português para designar que não há inclusão, que o significante da lei está fora do circuito, sem deixar, no entanto, de existir, pois o que está foracluído no simbólico retorna no real" ( $p$. 17). De maneira mais específica, na psicose, a foraclusão do Nome-do-Pai corresponde a um rechaço ao registro simbólico, implicando a não travessia da epopéia edipiana, já que o sujeito não foi submetido à castração simbólica. A foraclusão remete a noção da lei e da sua abolição.

De acordo com Lacan (1957-1958/1999), esta é a questão preliminar a todo tratamento possível em psicanálise. O Nome-do-Pai é o significante que marca a entrada na linguagem e articula uma cadeia de significantes. A ausência na inscrição desse significante acarreta aquilo que para Lacan marca a característica singular da psicose, sua interação própria com a linguagem, ocasionando distúrbios de linguagem e as alucinações. 
Os distúrbios da linguagem dão margem para interpretar que, ainda de seu modo próprio, o sujeito psicótico inserido na cultura, se vale da linguagem, porém, a partir de perspectivas particulares. Não é à toa que, o psicótico estabelece modos de comunicação com o mundo externo a partir do que convém sua realidade psíquica (Lacan, 1995-1956/1985).

Lacan (1955-1956/1985) ainda no Seminário 3, As Psicoses tece comentário sobre a relação do psicótico com a linguagem e argumenta que mesmo esta sendo delirante, há discurso:

É justamente em que essa linguagem pela qual podemos nos deixar surpreender no primeiro contato com o sujeito, algumas vezes mesmo o mais delirante, leva-nos a ultrapassar sua noção, e a admitir o termo discurso. Pois, seguramente, esses doentes falam a mesma língua que nós. Se não houvesse esse elemento, não saberíamos absolutamente nada deles. É, portanto, a economia do discurso, a relação da significação com a significação, a relação de seu discurso com o ordenamento comum do discurso, que nos permite distinguir que se trata do delírio (Lacan, 1995-1956/1985, p.44).

A marca do Lacan (1955-1956/1985) estruturalista já apresenta que a psicose nas particularidades de sua estrutura estabelece laço com aquilo externo a sua realidade psíquica. Ainda que de maneira rudimentar, o sujeito psicótico significa, a partir de suas possibilidades, as experiências que lhe tomam o corpo. Neste lugar, já se indica a aposta da inscrição da psicose no discurso, tendo como ponto de partida a identificação daquilo que se trata o delírio, fazendo deste um modo de enfrentamento ao insuportável, de comunicação e de laço com o mundo externo.

A estrutura psicótica não se estabelece por deficiência biológica-sensorial, mas pela precarização de mediação do simbólico. Pode-se dizer que se trata da clínica do real, daquilo que se faz sentir na dimensão corporal de modo direto, sem nomeação ou representação. A psicose revela algo da angústia que domina o corpo maciçamente, sem nome ou explicação, dando provas da irrupção de um real sem lei. Conquanto, se o Outro neurótico é "mudo", representado, isso implica que seu discurso atravessa o muro da linguagem, através de formações inconscientes, lapsos, atos faIhos, sonhos etc. Por sua vez, na psicose o Outro fala, aparece sem representação, provocando reações à nível corporal de sentir-se fragmentado, tomado por algo que não corresponde a um Eu. Isso faz com que o sujeito psicótico, contrário ao neurótico que habita a linguagem, "seja hábito pela linguagem" (Quinet, 2014, p. 18).

O Outro para o neurótico é inconsciente, pois é barrado pelo significante de castração, contendo, portanto, uma falta. O Outro falta para o neurótico, falta por ele ser inconsistente. Já para os psicóticos, o Outro não é barrado, é consistente. O sujeito na paranoia dá-lhe atribuição subjetiva, nomeando seja aquele que, de longe, emite ondas que se transformam em vozes ordenando-Ihes coisas, seja aquele médico que lhe injuria e Ihe faz proposições obscenas. O outro psicótico, por carecer do significante da lei, é um Outro absoluto ao qual o sujeito é submetido (Quinet, 2014, p. 18).

Pode-se dizer que, a particularidade psicótica revela, aquilo que a estrutura neurótica mantém em segredo (Lacan, 1964/1979). Assim, o significante foracluído no simbólico retorna no real sob forma de delírio. Nessa mirada, o ensino de Lacan (19751976/2007) nos permite considerar o delírio como um discurso articulado. O rito neurótico da metáfora paterna equivale, na psicose, ao advento da metáfora delirante, "trata-se de uma combinação de elementos onde a intenção de situar o fenômeno elementar assume um valor" (Miller, 2005, p. 2). O delírio é uma resposta diante dos impasses que retornam no real, caracterizando-o pela proliferação de elementos imaginários, na tentativa de mediação à significação fálica da qual carece.

A ênfase freudiana da função do delírio como tentativa de cura e como remendo na relação do sujeito com a realidade é elucidada neste prisma, onde o delírio representa o mundo imaginário em estado desenvolvido. É por essa via que o psicótico tenta organizar alguma integração simbólica.

O que se avista no processo de elaboração de um sistema delirante é uma tentativa de reconstrução por meio do qual o psicótico, sem o suporte da significação fálica, lida com a estrutura da linguagem, 
ensaiando alguma produção de sentido que o sustente psiquicamente. Na clínica, cabe ao analista assessorar e acompanhar o frágil equilíbrio delirante do psicótico, ao invés de demonstrar determinações inconscientes na esfera da suposição de saber, consolidando uma rede de sentidos capaz de protegê-lo de ser tomado pelo furo do real, sempre iminente (Lacan, 1975-1976/2007).

Cabe ressaltar que, nem todo psicótico consegue se organizar através de uma ficção delirante tão sofisticada quanto aos escritos de Schreber (Freud, 1911/2010b). O delírio é sempre uma metáfora frágil simbolicamente, embora, assim como o sintoma neurótico, seja uma solução singular para um conflito psíquico.

Miller (2003a) distingue o uso comum do termo delírio, em seu sentido patológico, do delírio normal. Ambos são ficções sociais e podem, por isso, ser qualificados dessa maneira. Segundo o autor, são montagens que resolvem problemas colocados pelo aparelho psíquico. O diferencial dos delírios psicóticos é que "eles são obrigados a fazer esforços totalmente desmedidos para resolver problemas que, para o normal ou o neurótico, são resolvidos, pelos discursos estabelecidos" (Miller, 2003a, p. 15).

Na experiência psicótica, significante e significado se apresentam de forma completamente dividida, o que também se evidencia na clínica da neurose. Isso permite a Lacan elucidar que a propriedade do significante é de ser segmentado, que não há cola entre o significante e o significado, sendo esse o vínculo sempre arbitrário. Nessa direção, a significação se faz a partir de uma mínima, S1 - S2, permitindo ver, desse modo, que todo sentido produzido é delirante, seja na neurose ou na psicose. Nesse contexto, "falar de delírio não é somente falar de delírio de interpretação, mas sim que o delírio é uma interpretação" (Miller, 2005, p.19). Assim, tal qual o sintoma neurótico porta um sentido inconsciente a ser desvelado na prática analítica, a construção de um delírio na psicose marca a produção de um sentido que se faz pautado na foraclusão e no modo particular de construção da realidade, sem contar com o Nome-do-Pai.

O delírio psicótico denota um esforço de invenção do Um-sozinho, sem Outro, em uma lógica não compartilhada. Lacan (1958/1998) aborda a loucura de Schreber em sua tese de que o psicótico não está fora da linguagem e a reafirma no seu seminário sobre o sinthoma, tomando o escritor James Joyce (Lacan, 1975-1976/2007) como um novo paradigma para pensar a foraclusão e seus efeitos de laço. Destaca aí que a psicose guarda uma relação direta com o significante, o suporte material da linguagem, apresentando-o em sua forma radical, pura, sem se remeter a mais nenhuma significação.

Em seu último ensino, iniciado nos anos 70, Lacan (1975-1976/2007) propõe uma mudança no estatuto do sintoma. Se, antes, o sintoma partia da ordem do deciframento, nessa outra conjuntura, a ênfase é colocada na vertente do gozo do sintoma. O sinthoma é pensado como um modo ou uma fixação de gozo, algo que faz amarração (Miller, 1998).

Lacan (1975-1976/2007) desenvolve pontos teóricos que permitem elaborar que há outra forma de ordenação da subjetividade que não passa, necessariamente, pelo Nome-do-Pai, encontrando suporte em outros elementos que apresentam estrutura de sintoma, dando margem a outra forma de compreensão sobre a psicose. Nesse momento da teoria lacaniana, Miller (1998) sublinha que o Nome-do-Pai nada mais é que um sintoma, assim, ambos respondem ao real de suas operações, localizando ou fixando o gozo.

Conforme referido por Miller (1998), Lacan (19751976/2007) estabelece outro estatuto à noção de sintoma, apostando em uma relação do sujeito com a linguagem de forma a ter que inventar o Outro que não existe, valendo-se da psicose para exemplificar as variadas e inéditas formas de invenção que os psicóticos necessitam fazer. A invenção, que é a construção de uma função original e diversificada diante daquilo que não existe, adquire maior propriedade, pois o psicótico testemunha essa inexistência e, se pode dizer, o faz sem recurso a nenhum discurso estabelecido, tendo que inventar uma função ou uma relação inédita (Miller, 2003a). Assim, é importante pensar a relação do psicótico com a linguagem, pois se sua relação for de exterioridade, não se pode esquecer que ele tem contato com os variados discursos estabelecidos do mundo, circula pela sociedade e estabelece laço com aquilo que condiz com sua realidade, havendo, assim, a possibilidade de se valer dos discursos como parceiros possíveis para se inserir no signo social. 
$\mathrm{Na}$ esteira das reformulações e avanços do último Lacan (1975-1976/2007) a psicanálise parte da psicose como paradigma de leitura do contemporâneo. Os novos sintomas são compreendidos como manifestações que não fazem apelo à decifração e que se apresentam em vertente de gozo desvelado, sem semblante e sem revestimento simbólico. Dessa forma, os novos sintomas não se estruturam pela norma edipiana. Pensar o sintoma mais além da função paterna nos orienta para a psicose, compreendida como estrutura possível onde não há relação sexual, pois a própria linguagem já aponta para algo que resta de não-articulável na cadeia significante, podendo esse resto circular por outras vias, inventadas, criadas, despojadas do semblante paterno (Miller, 2000).

Miller (2003b) estabelece dois momentos na clínica, o primeiro deles nominalista, quando se recebe o paciente em sua singularidade, sem compará-lo, inclassificável por excelência; e outro momento estruturalista, ao passo que cada estrutura demonstra uma articulação específica com os registros simbólico, imaginário e real, modo como cada um faz laço e produz sintomas. Entretanto, a interlocução do singular ao estrutural "permite, sobretudo, conhecer a relação do sujeito com o Outro, sem que, por isso, o mais autista de seu gozo deixe tudo descoberto (Arenas, 2011, p.7).

O laço social é uma possibilidade de parceria na qual o psicótico poderá se alojar. É possível apresentar a hipótese de que o sujeito poderá circular, ou se inserir, em algum discurso a partir de sua construção particular, pensadas no final do ensino de Lacan, onde ele apresenta que há outras formas de estruturação da subjetividade que não passam pelo Nome-do-Pai. É através do sinthoma, modo singular que cada ser de fala trata seu gozo, que pensaremos o laço social na psicose (Miller, 2003b).

\section{Considerações finais}

A clínica psicanalítica se apresenta como possibilidade de inserção da loucura no meio social, por basearse, senão, no distanciamento de proposições universalistas e de classificações identificatórias. A clínica do sintoma aproxima-se da clínica do real e da alternativa singular de cada sujeito de fala se estabelecer no laço social, seja pelo discurso médico, religioso, artístico etc. (Generoso, 2008).

A psicanálise se debruça onde há um vazio, local que o discurso demagógico, científico e intelectual não alcança. O exercício psicanalítico só se torna possível pois a linguagem está para todos, sendo o sujeito do inconsciente quem organiza, a partir da sua estrutura psíquica, as possibilidades de fazer laço (Miller, 2005). É justamente aí que se encontra a grandeza de um fazer sutil e singular: seja na direção do tratamento na neurose ou na assessoria e testemunho de sua verdade inventada na psicose a aposta psicanalítica no inconsciente sempre demonstra uma invenção política de cada um às amarras sociais que regem e anulam o ser social do gozo sem medidas.

A partir da consideração que há possibilidade de laço social na psicose é possível rever o processo de reinserção social não só para aqueles que sofrem sua ausência da norma edipiana, mas compreender como o sujeito, seja neurótico ou psicótico, fia-se no tecido social segundo modos particulares de entrar no discurso, nos permitindo, assim, refletir sobre a própria exclusão social.

Ao tomar o conceito de laço social como um modo de entrar no discurso, podemos problematizar a intolerância ao diferente, o repúdio à alteridade evidente, o preconceito contra a loucura e seus efeitos de restrição à liberdade. Essa perspectiva convoca para o primeiro plano o sujeito de direito e responsabilidade, que constrói seu sinthoma, sempre singular. 


\section{Contribuições dos autores}

Bastos MCC participou da revisão bibliográfica, fez a discussão e articulação dos resultados obtidos, assim como a redação do artigo. Barros RA participou da revisão e contribuiu com a redação do artigo.

\section{Conflitos de interesses}

Nenhum conflito financeiro, legal ou político envolvendo terceiros (governo, empresas e fundações privadas etc.) foi declarado para nenhum aspecto do trabalho submetido (incluindo, mas não se limitando a subvenções e financiamentos, participação em conselho consultivo, desenho de estudo, preparação de manuscrito, análise estatística etc.).

\section{Referências}

Aguiar, A. (2020). Da psicopatologia de Jaspers à biologia lacaniana. In A. Teixeira, \& M. Rosa (Orgs), Psicopatologia lacaniana: nosologia. Autêntica.

Arenas, A. (2011). A saúde de todos, sem a segregação de cada um. In Associação da Fundação do Campo Freudiano (Orgs.), A saúde de todos, não sem a loucura de cada um: perspectivas da psicanálise. Wak.

Barreto, F. P. (2007). A psicanálise Aplicada à Saúde Mental. Clinicaps, (1), 1-28. https://pesquisa.bvsalud.org/portal/ resource/pt/psi-45262

Basaglia, F. (1991). A Instituição Negada. Graal.

Berenguer, E. (2011). A loucura de cada um na contemporaneidade: de perto ninguém é normal. In Associação da Fundação do Campo Freudiano (Orgs.), $A$ saúde de todos, não sem a loucura de cada um: perspectivas da psicanálise. Wak.

Calazans, R., \& Bastos, A. (2008). Urgência subjetiva e clínica psicanalítica. Revista Latinoamericana de Psicopatologia Fundamental, 11(4), 640-652. https://doi.org/10.1590/ S1415-47142008000400010

Canguilhem, G. (2009). O Normal e o Patológico. Forense Universitária. https://app.uff.br/slab/uploads/ GeorgesCanguilhem-ONormaleoPatologico.pdf
Cervo, A. L., \& Bervian, P. A. (1983). Metodologia científica: para uso dos estudantes universitários. McGraw-Hill do Brasil.

Coelho, C. M. S. (2006). Psicanálise e laço social - uma leitura do Seminário 17. Mental, 4(6), 107-121. http://pepsic.bvsalud.org/scielo.php?script=sci_ arttext\&pid=S1679-44272006000100009

Foucault, M. (1978). História da loucura na Idade Clássica. Perspectiva.

Freud, S. (1980). Os caminhos da formação dos sintomas. Imago. (Texto originalmente publicado em 1917)

Freud, S. (1996). A perda da realidade na neurose e na psicose. Cia das Letras. (Texto originalmente publicado em 1924)

Freud, S. (2010a). O Mal-Estar na Civilização. Cia das Letras. (Texto originalmente publicado em 1930).

Freud, S. (2010b). Observações psicanalíticas sobre um caso de paranoia. Relato em autobiografia - O caso Schreber. Cia das Letras. (Texto originalmente publicado em 1911)

Freud, S. (2016). Estudos sobre a Histeria. Cia das Letras. (Texto publicado originalmente em 1893-1895).

Garcia-Roza, L. A. (2009). Freud e o Inconsciente. Jorge Zahar.

Gaspard, J. L. (2012). Discurso Médico e Clínica Psicanalítica: colaboração ou subversão. Cia de Freud.

Generoso, C. M. (2008). Considerações sobre a psicose e laço social: o fora-do-discurso da psicose. Clinicaps, 2(4), 1-10. http://pepsic.bvsalud.org/scielo.php?script=sci_ arttext\&pid $=$ S1983-60072008000100003

Generoso, C. M. (2014). Psicose, desinserção e laço social: um debate entre a psicanálise e o campo da saúde mental [tese de doutorado, Universidade Federal de Minas Gerais]. Repositório da Universidade Federal de Minas Gerais. https://repositorio.ufmg.br/handle/1843/BUBD-9WXFNN

Gil, A. C. (2008). Métodos e técnicas de pesquisa social (6 $6^{\mathrm{a}}$ ed). Atlas.

Guéguen, P. G. (2011). Quem é louco e quem, não é? Sobre o diagnóstico diferencial em psicanálise. In Associação da Fundação do Campo Freudiano (Orgs.), A saúde de todos, não sem a loucura de cada um: perspectivas da psicanálise. Wak. 
Lacan, J. (1979). O Seminário, livro 11: Os quatro conceitos fundamentais da psicanálise. Jorge Zahar. (Texto originalmente publicado em 1964)

Lacan, J. (1987). Da psicose paranoica em suas relações com a personalidade. Forense Universitária. (Texto originalmente publicado em 1932)

Lacan, J. (1992). O seminário, livro 17: O avesso da Psicanálise. Jorge Zahar. (Texto originalmente publicado em 1969-1970).

Lacan, J. (1997). O Seminário, livro 7: a ética da psicanálise. Jorge Zahar. (Texto originalmente publicado em 1959-1960)

Lacan, J. (1998). De uma questão preliminar a todo tratamento possivel das psicoses. Escritos. Jorge Zahar. (Texto originalmente publicado em 1958)

Lacan, J. (1999). O Seminário, livro 5: as formações do inconsciente. Jorge Zahar. (Texto originalmente publicado em 19571958)

Lacan, J. (2003). Outros escritos. Jorge Zahar. (Texto originalmente publicado em 1974)

Lacan, J. (2007). O Seminário, livro 23: O sinthoma. Jorge Zahar. (Texto originalmente publicado em 1975-1976)

Lacan, J. (2008). O Seminário, livro 7: A Ética da Psicanálise. Jorge Zahar. (Texto originalmente publicado em 1957-1958)

Laurent, E. (2017). Gênero e Gozo. Revista Escola Brasileira de Psicanálise, (44), 43-55. https://encontrobrasileiro2018. com.br/genero-e-gozo/

Maher, W. B., \& Maher, B. A. (2011). Um esboço da história da psicopatologia. In Manual de psicopatologia e transtornos psicológicos. Pirámide. https://doi. org/10.13140/2.1.5172.2244

Mendes, A. A. (2005). Tratamento na psicose: o laço social como alternativa ao ideal institucional. Mental, 3(4), 15-28. http://pepsic.bvsalud.org/scielo.php?script=sci arttext\&pid=S1679-44272005000100002\&lng=pt\&tlng=pt

Mezêncio, M. S. (2004). Metodologia e pesquisa em psicanálise: uma questão. Psicologia em revista, 10(15), 104-113. https://pesquisa.bvsalud.org/portal/resource/pt/lil-478099
Mezza, M. (2018). A teoria da loucura em Lacan como crítica ao patetismo da doença mental. Estudos de Psicanálise, (49), 139-148. http://pepsic.bvsalud.org/scielo.php?script=sci_ arttext\&pid=S0100-34372018000100013

Miller, J. A. (1981). Lacan elucidado. Jorge Zahar.

Miller, J. A. (1998). Os casos raros, inclassificáveis, da clínica psicanalítica: a conversação de arcachon. Biblioteca Freudiana Brasileira.

Miller, J. A. (2000). Os seis paradigmas do gozo. Opção lacaniana, 26(27), 87-105. http://opcaolacaniana.com.br/pdf/ numero_7/Os_seis_paradigmas_do_gozo.pdf

Miller, J. A. (2003a). A invenção Psicótica. Opção Lacaniana, 36, 6-16. http://www.mom.arq.ufmg.br/mom/03_casas loucos/04-referencias/textos/textos\%20psicanalise/ invencao

Miller, J. A. (2003b). O último ensino de Lacan. Opção Lacaniana. Edições Eólia. https://www.ebp.org.br/old/publicacoes/ opc\%CC\%A7a\%CC\%83o-lacaniana-35/

Miller, J. A. (2005). Silet: os paradoxos da pulsão, de Freud à Lacan. Jorge Zahar.

Miller, J. A. (2011). Saúde mental e ordem pública. In Associação da Fundação do Campo Freudiano (Orgs.), A saúde para todos, não sem a loucura de cada um: perspectivas da psicanálise. Wak.

Miller, J. A. (2012). Scilicet: A ordem simbólica no século XXI não é o que costumava ser. Que consequências para a cura? École de la Cause freudienne.

Miller, J.A. (1999). Saúde Mental e Ordem Pública. Curinga, 13, 20-21. https://pt.scribd.com/doc/80073172/02-a-cidadeanalitica-saude-mental-e-ordem-publica-jacques-alain$\underline{\text { miller }}$

Minayo, M. C. S. (1994). Pesquisa social: teoria, método e criatividade. Vozes.

Pereti, L. Z. (2011). O sujeito psicótico e sua posição em relação ao laço social: as contribuições de Jacques Lacan até o período do Seminário III - As Psicoses [dissertação de mestrado, Pontifícia Universidade Católica de São Paulo]. Repositório da Pontifícia Universidade Católica de São Paulo. https:// repositorio.pucsp.br/jspui/handle/handle/16930 
Porge, E. (2006). Jacques Lacan, um Psicanalista: percurso de um ensino. Editora Universidade de Brasília.

Quinet, A. (2014). Psicose e laço social: Esquizofrenia, paranoia, melancolia. Jorge Zahar.

Quinet, A. (2018). Teoria e clínica da psicose. Forense Universitária.

Recalde, M. (2011). Nem igual nem excepcional: "ninguém é normal de perto". In Associação da Fundação do Campo Freudiano (Orgs.), A saúde de todos, não sem a loucura de cada um: perspectivas da psicanálise. Wak Editora.

Rodrigues, A. C., Costa, C. A. R., Silva, M. E. A., \& Silva, E. P. (2005). Psicanálise, saber e conhecimento. Revista do Departamento de Psicologia, 17(2), 199-108. https://doi. org/10.1590/S0104-80232005000200009
Safatle, V., Silva Junior, N., \& Dunker. C. (2020). Patologias do social: Arqueologias do sofrimento psíquico. Autêntica.

Seldes, R. D. (2019). A urgência do assunto. Colección Diva.

Silva, J. L. P., \& Derzi, C. A. M. (2019). Dos manicômios aos serviços substitutivos: a possibilidade do laço social na psicose pelo discurso da psicanálise lacaniana. Pretextos, 4(8), 164180. http://periodicos.pucminas.br/index.php/pretextos/ article/view/18641

Tendlarz, S. E. (2007). O inclassificável. In E. Alvarenga (Org.), A variedade da prática: do tipo clínico ao caso único em psicanálise. Contracapa Livraria.

Voruz, V. (2009). Democracia e psicose ordinária. Latusa Digital, 38, 1-16. 